\title{
Moving your library? Embrace the challenge, love the opportunity!
}

\author{
Kris Paterson \\ Brighton Grammar School \\ 90 Outer Crescent, Brighton VIC 3123 \\ Australia \\ kpaterson@brightongrammar.vic.edu.au
}

\begin{abstract}
The highs and lows of design, planning and moving an established school library into a brand new facility, designed for 21st Century teaching and learning at a boys' high school. Consultation, collaboration, big picture planning, flexibility and a sense of humor will get you through!
\end{abstract}

Keywords: Libraries, Secondary schools, 21st Century learning, Australia

\section{Introduction}

Brighton Grammar School is an independent school in Melbourne, Australia. Established in 1882 in the bayside (Port Phillip Bay) suburb of Brighton, it educates 1,250 boys from the age of 3-4 years until ages 17-18 (Prep-Year 12).

In 2011 the school announced its intention to undertake a significant building project, a new Middle School adjacent to the (then in use) Rosstrevor middle school campus. The Middle School supports some 25 staff to deliver the educational and learning needs of 300 students aged 12-14 (years 7 and 8). But what kind of building project to deliver? The school's extensive research and community discussion highlighted the need to build a Middle School that would 'be responsive to the learning needs and preferences of Year 7-8 boys for 2014 and well beyond.

\section{Philosophical issues}

The old Middle School library of 2013 and the years before was positioned on the other side of an outdoors 'quadrangle' playing area, that forced students who wished to visit at recreational periods to navigate the enthusiastic and busy sporting activities in the quad to an upstairs room the size of 1.5 'typical' classrooms. When classes visited for reading or research, it had densely packed shelving, heavy tables, and minimal space for unstructured activities. The new library is strategically located at the entrance of the new Middle School (An AU\$19 million dollar project). It is impossible to enter the Middle School teaching and learning areas without passing the library's open foyer. The library is at ground floor, an open space, featuring floor to ceiling windows that look out onto a garden, with clear eye lines above chest height shelving, relaxed and flexible furniture fittings, with collaborative and breakout spaces.

The key challenge was moving from the old to the new in a tight timeline while reducing the physical collection to fit a reduced shelving capacity. This was done following a review of services, collection and curriculum needs, and consultation with subject leaders. In the 
background there was constant negotiation on shelving space, hiring contractors for the actual physical move, negotiation with the builder over access to the new facility, and hiring support staff to assist with the collection audit.

\section{Metrics of the move}

\section{Timeframe}

The school year ended 12 December 2013, by which time the old library had to be empty so building work to repurpose that space could occur over the summer holidays. At the same time, collection storage for the six weeks of summer had to be arranged as the new building access date was in the New Year, on 21 January 2014. A removal consultant from a professional library moving service was invaluable in providing advice regarding the size of the move, time involved, and moving options to pack, move, store and unpack both the required and the surplus stock.

\section{Shelving and discussions over space}

The library of 2013 was a modest collection of print and eBooks utilizing 141 shelf meters made up of $69 \mathrm{~m}$ fiction, $56 \mathrm{~m}$ non-fiction, and some $25 \mathrm{~m}$ of class set texts.

The new library was to provide 'plenty of space' but there was no identified shelf capacity in the initial plan.

"How much shelving?" "There's plenty of shelving" "But how MUCH shelving" was a circuitous discussion point with middle management. The initial proposal would have seriously compromised the scope and size of the collection.

The challenge was how to optimize shelving capacity without sacrificing eyelines and open space. It was necessary to draft a visual picture of shelving options tied to shelf space and its impact on the collection and requirements of the teaching departments.

The agreed design maintained eyelines and open space, and provided $62 \mathrm{~m}$ of shelving. This required a rigorous review of the collection.

\section{Collection reduction}

With the requirement for reduction it was vital to take a serious look at the library services, collection, and curriculum needs. The library offered a broad collection of recreational reading material (fiction, graphic novels) that were borrowed by students during reading classes and their own personal borrowing time, however the non-fiction collection and reference materials had minimal circulation; they were borrowed minimally, and resources on topics outside of assessed content as taught in the curriculum were barely touched, regardless of how shelves were rearranged to outward facing display, or how special interest displays might be created (by teacher-librarian or library committee of students).

With a brand new facility being built, it was important to devise a plan where the library could be an engaging and friendly space, and with the ground floor very visible location we would need a drawcard. With plenty of shelving being installed across the entire new Middle School the library needed a focus. Instead of a 'drastically reduced fiction and non-fiction collection... we could focus on creating a recreational reading hub and disperse the nonfiction collection to the learning commons (classroom) areas making the [curriculum] materials available at point of need This plan appealed to management in four aspects;

- it was proactive as recommended by La Marca a 'are you actually being proactive? Actually saying ok, this is the library I want...' 
- it had a vision for how the library could be, and how that would drive change in its use, and student learning

- it retained the relaxed, comfortable feel they wanted at such a priority viewing area of the school,

- supported the changes planned to classrooms being more flexible spaces, where students and teachers could be supported in situ, at their point of need.

\section{Identifying core requirements - consultation}

It was necessary to meet with curriculum leaders to discuss their department's curriculum, any changes to subject content or research priorities planned for the new team teaching style and new building, and identify what supporting documents they had that would specify that information. At a busy time of year, it was critical to get curriculum leaders on side, coffee and cake is always a good strategy, and rather than lead with the "I need help from you", it was more productive to come from a "how can the library and I support you and your teaching team to prepare for next year".

Reading lists were compiled, curriculum topics were identified. This led to a plan for resource procurement (with online materials being a priority), and the library management system was used to access reports of heavily used and non-circulating stock as well as the age of collection.

Based upon the timeframes, staffing available, and access limitations to the new building, the plan was developed that the removalists would install the collection selected for the new library. The collections intended for the classrooms would be packed into storage and dealt with later.

A collection audit was planned so that only current, authoritative materials were retained. Materials were selected based on their content, language and layout suited to our student demographic.

\section{Resources/support required}

\section{What tasks/what resources}

A firm specializing in library moves was contracted for the task. The removalists pack in shelf order, this allowed packed books to be relocated easily. The library kept separate records of the Dewey numbers in each shelf.

Temporary offsite storage for six weeks was required due to the time gap between compulsory exit of old library and access date to the new library.

External librarian labor was contracted for a period of 4 weeks to assist in completing the collection audit. The task included updating the catalogue to reflect the new locations and dispositions of the library stock. 4,000 books (111 boxes) were reviewed. Those meeting the criteria for currency, authority, curriculum needs and condition were selected for retention, and allocated to an appropriate classroom. Items identified as not appropriate for our requirements were sorted as either appropriate for donation or discard.

\section{Celebrating the achievement/opening}

The new Middle School, the Urwin Centre for Learning, was launched to all staff of the school at the commencement of the 2014 academic year. All school staff attended tours and experienced the learning commons classrooms in use during professional development workshops. 
The center was launched to the school in phases, with separate starting days for both year 7 and 8 , and an evening ceremony where the building was officially opened.

The library celebrations were student and staff inclusive. New book displays, Valentine's celebrations, pop up hub libraries all contributed to a sense of energy, welcome and celebration.

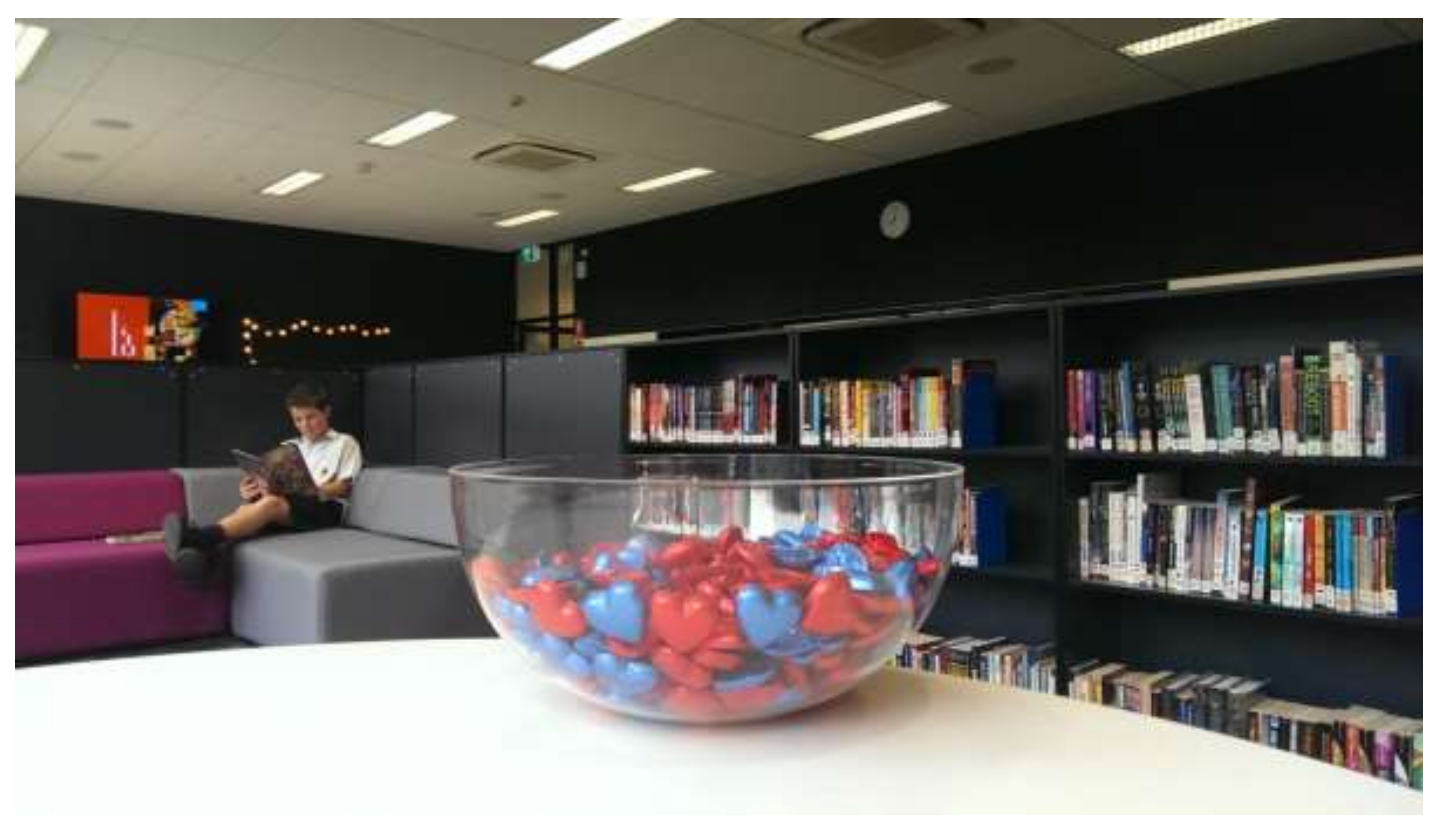

Figure 1. Valentine's Day welcome

\section{The new experience - measures of success}

The success of the move has been demonstrated by increased use of the library space by student visitors before school, at recess, lunchtimes and after school.

Increased borrowings by $20 \%$ remained consistent for the entire first year of operation. This was a statistic that was shared with management and English department. It showed concrete evidence of changed student behavior in the new environment.

Before school visitor average has doubled due to Study Club and the productive use of the space before school.

The number of boys visiting at recreational periods to read has increased. The new facility has doubled the amount of comfortable couch-style furniture, and boys can stretch and lean without hitting shelving.

Chess playing numbers have doubled, supported by the hosting of weekly lunchtime coaching organized by Learning Strategies department.

Additional activities have been scheduled in the library space including Homework Club and a reinvigorated Book Club operating as a joint venture with our sister girls' high school. Library activities are regularly publicized in the school newsletter. 


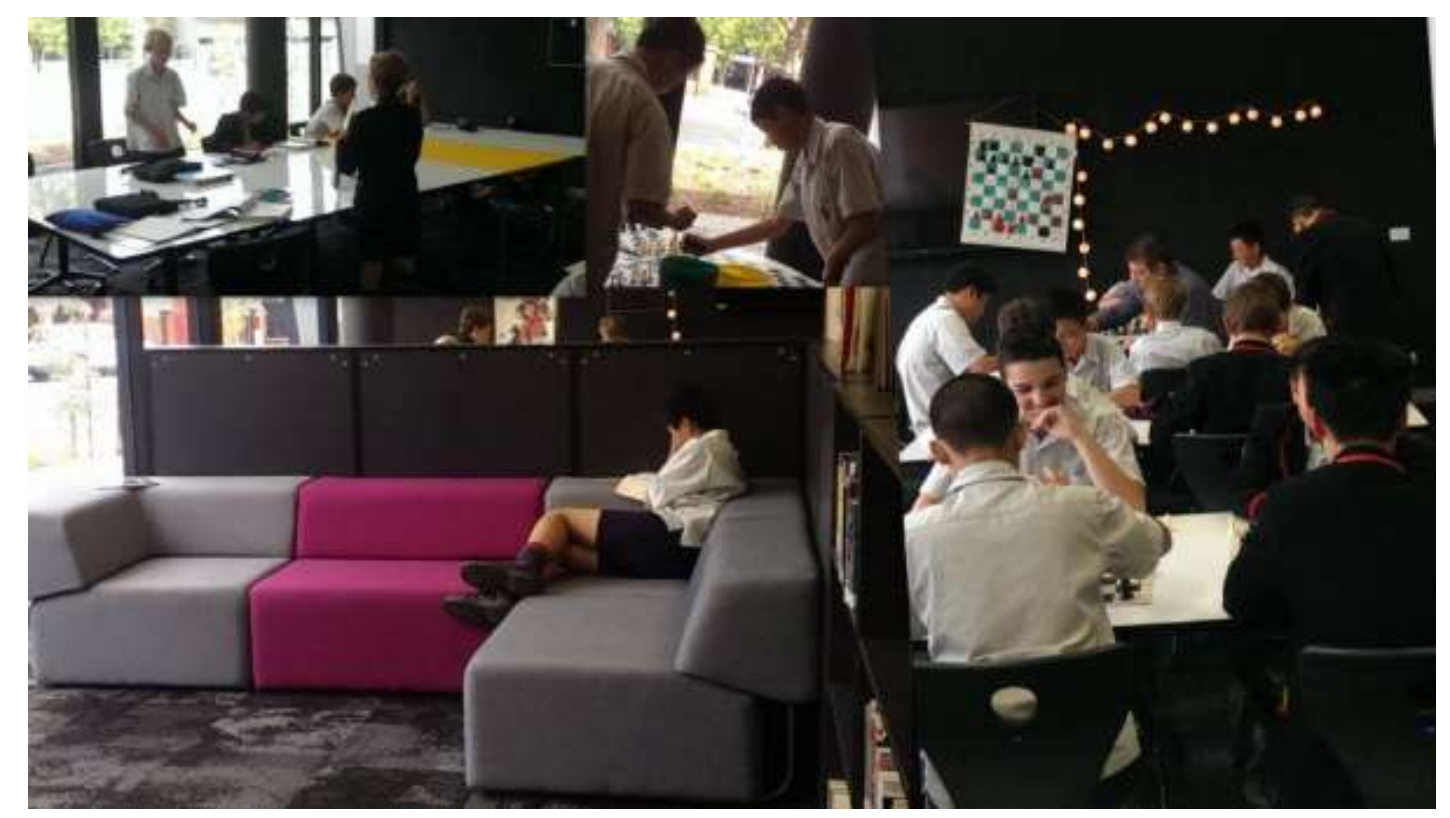

Figure 2. Montage of lunchtime in the library

\section{Conclusion}

\section{Lessons learnt}

The library service should be involved with the architects as early as possible in the planning. Measures of shelving, space, accommodation style need to be determined early. The close down, movement and commissioning of the library need to be adequately resourced. Continuous publicity to the school community during the construction, occupation and operational phases is essential.

Determine your measures of success early

Document everything with photos and keep everyone informed of strategic milestones.

Regardless of research and planning it takes time for all the parties involved in the library service to make best use of a new facility. This is an ongoing process and we are enjoying the journey.

\section{References}

Crowther Centre for Learning and Innovation. (2012). 21st Century Learning, Flexible Learning Spaces and Middle Schooling: Green Paper. Melbourne: Brighton Grammar School.

La Marca, D. S. (2010). Podcast of Dr Susan La Marca's SLAQ-IASL 2010 Conference presentation. Queensland, Australia.

Paterson, K. (2014). A New Style of Library for a New Style of Learning - Brighton Grammar School's Middle School Library Services. Retrieved from Synergy: http://www.slav.vic.edu.au/synergy/volume-12-number-1-2014/perspectives-local/363-a-new-style-of-library-for-a-new-style-of-learning-brighton-grammar-schoolsmiddle-school-library-services.html 


\section{Biographical note}

Kris Paterson BEd, PGradDip (Comp Studies), MBIT

Kris has worked in libraries for 18 years, and has led secondary school libraries in regional and metropolitan Victoria, Australia. She recently spent two years working in the tertiary sector at a multi-campus university library, and is currently Middle School teacher-librarian at Brighton Grammar School, a day school for 1,250 students from Prep to year 12. Her work there includes collaborating with teachers, and designing, delivering and evaluating information literacy and reading programs. 